\title{
RETORNO DE PADRES Y/O MADRES MIGRANTES INTERNACIONALES DESDE LOS RELATOS DE HIJOS E HIJAS. SIGNIFICADOS DE LOS ACUERDOS Y LOS PROYECTOS FAMILIARES ${ }^{1}$
}

\author{
RETURN OF PARENTS AND/OR INTERNATIONAL MIGRANT \\ MOTHERS FROM THE STORIES OF SONS AND DAUGHTER. \\ ITS MEANINGS OF FAMILY PLANS AND AGREEMENTS
}

Por: Anatali Oquendo Lorduy

jadora Social (Uni-

dad de Cartagena)

cialista en Convi

a y Conflicto Social

rante del Grupo de

tigación: Estudios

milias, Masculi-

les y Feminidades,

rersidad de Cartage-

oven Investigadora

olciencias (2010

). Docente de la

ación Universitaria

mbo Internacional

a Corporación Uni-

taria Rafael Núñez

mbia). Es coautora

uaderno de trabajo

: Familias y diná-

s contemporáneas

os familiares desde

ir transnacional. I

li24@yahoo.es.

\section{RESUMEN}

Este artículo, aporta reflexiones sobre los estudios de migración internacional en Cartagena de Indias, a partir del análisis de experiencias de un grupo de hijos e hijas cuyos padres y/o madres han migrado por diversos motivos. En sus experiencias, se abordan los significados elaborados en torno al retorno, en particular aquellos sobre los acuerdos y proyectos familiares, que se movilizan a partir de los vínculos y expectativas que los migrantes van construyendo con hijos e hijas entre origen y destino, así como los cambios que pueden suscitarse, a lo largo del proceso migratorio, debido a la ausencia o presencia, que en conjunto lleven a reconfigurar sus expectativas de familias.

Palabras claves: Migración internacional, retorno, acuerdos, proyectos familiares, hijos e hijas, padres y madres migrantes.

\begin{abstract}
This article provides reflections on international migration studies in Cartagena de Indias, from the analysis of experiences of a group of children whose fathers and/or mothers have migrated for various reasons. In their experience, we study the meanings prepared for returns, particularly those on the agreements and family projects, that move from the links and expectations that the migrant, male or female, builds with their children, between origin and destination as well as changes that occur between these throughout the migration process, due to the absence or presence of the migrant, which together lead to reconfigure their expectations of families.
\end{abstract}

Keywords: International migration, return, agreements, family projects, sons and daughters, migrant fathers and mothers.

\section{Introducción}

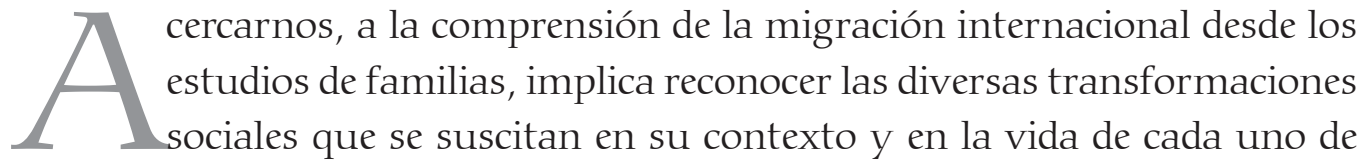
sus integrantes, que provocan cambios que dan cuenta de la pertenencia 

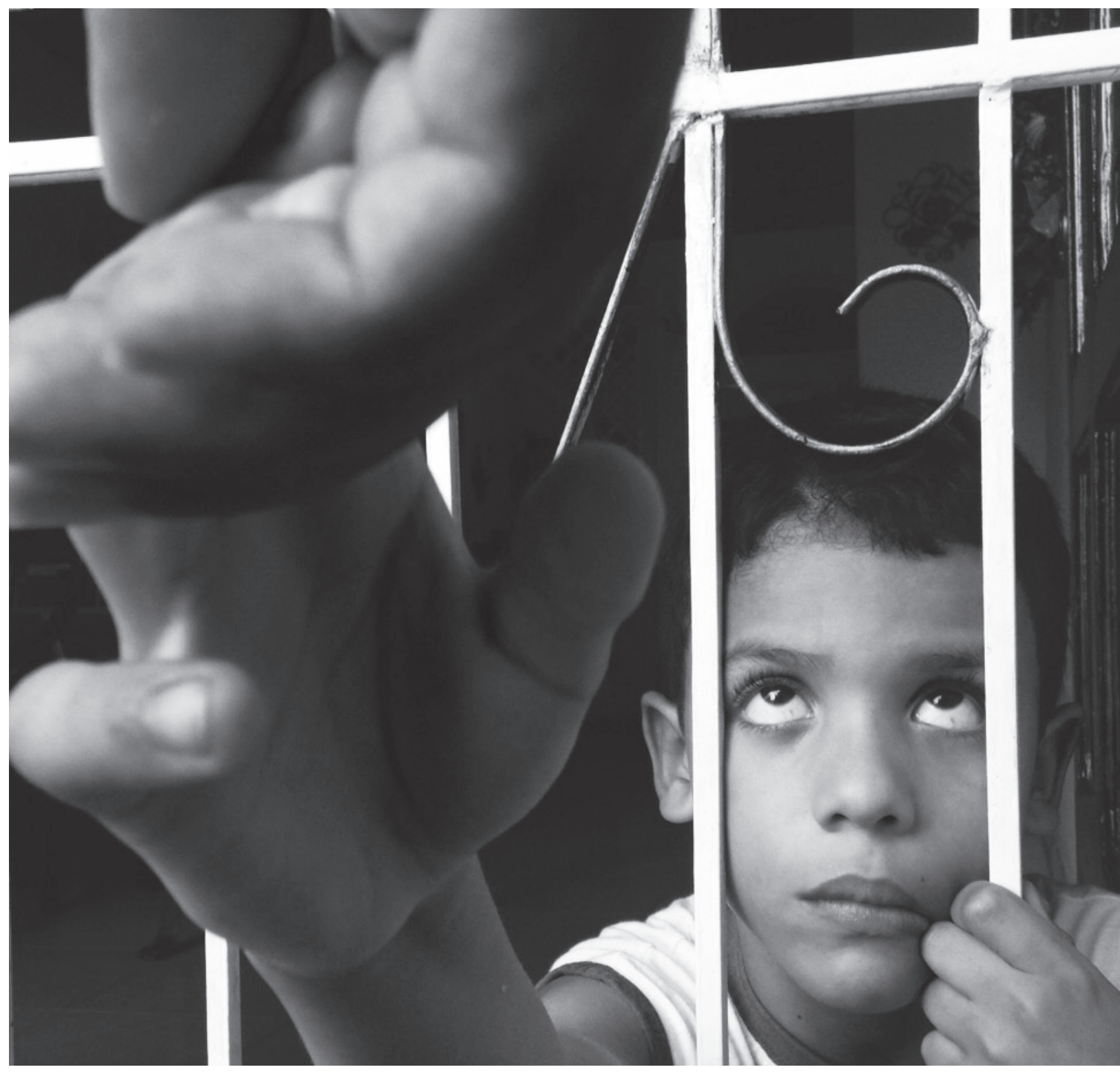

Foto: Shirley Qui

a una realidad histórica, cultural y política, que las enfrentan a nuevas dinámicas sociales, que irrumpen en las cotidianidades familiares, entre ellas la migración internacional, que constituye un proceso dinámico, que en el actual panorama de la globalización, permea los grupos familiares a partir de la creciente dinámica, en el incremento de movimientos migratorios, que impulsan la salida del país de origen de uno o más integrantes de las familias -padres y/o madres- debido a múltiples circunstancias, pudiendo ser estas de orden, social, económica, política o cultural.

En este sentido, la migración internacional en los grupos familiares, como proceso, se expresa desde el momento que se va concibiendo, la idea de su interés y capaci en el campo de la in gación científica. Ex gación cientifica. Ex
mis agradecimien mis agradecimien
los hijos e hijas ent tados/as por dejarr parte de sus hist por dejarme acarici experiencias vitale que hacen parte de l intimo de su ser, $y$ me comprender construyen y recor yen incesantement de sus seres querido ellos y ellas no hi sido posible estas ref nes. Así mismo dezco a Julio Reye discusiones, exper y lectura, aporta
la consolidación d artículo. 
migrar, que posteriormente se moviliza con la partida, la llegada al país destino y el vislumbrar una pronta reemigración. Sin embargo, cada uno de estos momentos, en el proceso migratorio, no se expresan de forma lineal, pues no solo se hace referencia al movimiento de salida del país de origen, que constituye el primer proceso que trastoca y tensiona al grupo familiar, también hay que vislumbrar los contra-movimientos que esto implica, como el retorno o la reunificación, que pueden estar mediados por periodos cortos o prolongados de tiempo, por motivos como: las condiciones económicas o políticas de los países, los deseos o expectativas de el/la migrante, las relaciones parentofiliales, los nuevos arreglos familiares, entre otros, que se constituyen en elementos redefinidores del proyecto migratorio.

El retorno, pone en cuestionamiento el pretendido carácter unidireccional o definitivo de la migración, y por tanto constituye un aspecto importante, que debe ser explicado y tomado en cuenta a la hora de legislar, así como para comprender la movilidad humana (Durand, 2004:104). La decisión de retornar, de volver al origen, a la tierra donde se nació, y en la que se dejaron sentimientos de amor, desamores, proyectos familiares e individuales, constituye, al igual que el inicio del proyecto migratorio, una experiencia cargada de incertidumbres y tensiones. Porque, para quien retorna como para quienes se han quedado en origen, el retorno reinicia la migración en sentido inverso, lo que significa nuevamente transitar en la toma de decisión, la partida, el establecimiento de acuerdos y de estrategias para movilizar el regreso.

\section{Consideraciones conceptuales y teóricas: una mirada al tema del retorno}

ara acercarme un poco a las discusiones sobre el retorno en Colombia, retomo los datos de la Encuesta Nacional de Migraciones Internacionales

_ y Remesas 2008-2009, que muestra el total de hogares con personas emigradas siendo esta cifra cercana a las 553.787 y el de retornados a 534.943, colocando las dos temáticas en el mismo orden de magnitud (ENMIR, 2009:22). Estas cifras, evidencian que la migración en Colombia presenta un crecimiento significativo, tanto en el número de emigrantes como de retornados. Este panorama, expresa que no se debe desconocer la realidad de muchos migrantes, que hacen su maleta de viaje con la intención de un futuro mejor para ellos/as y sus familias, y se enfrentan a otras realidades, otros mundos y a otras vivencias, a pesar de las incertidumbres, riesgos y tensiones que esto implica. Y a su vez, muchos de ellos regresan a su país de origen, presionados por la precariedad económica, sentimientos de fracaso, éxitos alcanzados o los vínculos que provocan las relaciones familiares. 
No obstante, a pesar de lo paradójico que resulta ser la migración, el retorno aparece como un deseo presente al momento de la partida, y es que tal como lo plantea Durand, la mayoría de los migrantes parte del terruño pensando en volver (2004:107), pero regresar no constituye un hecho simple, ese cuándo regresar no se logra definir, pues quien migra si bien tiene cierta certeza sobre el momento de la partida, con el retorno sucede todo lo contrario, siendo este un evento incierto. Volver a origen, va a estar condicionado a la satisfacción, cumplimiento y consecución de un conjunto de objetivos, metas, proyectos y expectativas, que pueden ir aplazando el pronto regreso, el cual puede pasar de un periodo de tiempo corto a otro prolongando en años, haciendo que cambien los acuerdos iniciales frente al retorno, que pueden movilizarse en ese deseo de regresar hasta en concebir la idea de no volver, dado que nuevas circunstancias lo arraigan al nuevo destino.

Es importante comprender, que la migración de retorno está estrechamente ligada a una práctica cultural de arraigo al lugar de nacimiento, al cual están vinculados sentimientos de pertenencia, identidad y reconocimiento. El vínculo con el territorio de origen, se mantiene a través de las familias, los amigos y el entorno social, lo que refuerza los fuertes lazos con el lugar de origen; y la idea de migrar (dentro o fuera del país), para mejorar la condición económica y regresar en mejores condiciones al lugar de nacimiento, hace parte, del proyecto de vida, de gran número de personas (González, 2006:21). Por estas razones, es posible que padres y madres migrantes tengan entre sus expectativas, el deseo de volver a su tierra, porque siempre en origen queda algo que no es posible llevar más allá.

El/la migrante comienza a desarrollar así un doble vínculo, entre origen y destino, donde está presente el grupo familiar que se dejó y la nuevas experiencias aprendidas en la distancia. Pero el simular esta doble vinculación no es exclusividad del migrante, quienes se quedan, aunque permanecen físicamente aquí, intentan forjar una vinculación inmaterial con el/la migrante, que les permita, en la mayoría de los casos, compartir con este, sus angustias, soledad, tristeza, nostalgia y la melancolía que genera la partida y encontrarse en un lugar, en el que físicamente está el trabajo y el sustento para el/ella y su grupo familiar, pero donde escasamente se puede encontrar los afectos, amores y amistades. Por ello, para el/la migrante como para quienes se quedan cobran sentido los recuerdos, cómo revivirlos y el construir en la distancia un mundo simbólico e imaginario, que permitan disipar las distancias y en especial esas ausencias tanto corpóreas como emocionales. 
Se vive, entre aquí y allá, pero ante la idea de un posible retorno al grupo familiar, ambos pueden experimentar cambios, pues como lo señala Díaz, quien retorna viene cargado con otras experiencias de vida, comportamientos, valores y formas de actuar, y encuentra obviamente, cambios en lo que dejó y en las circunstancias que había al momento de su salida (2009:15). Estos cambios, pueden generar la sensación de encontrarse entre extraños, porque las ideas fijas antes de la partida, sufren transformaciones que se perciben con la llegada, enfrentando situaciones no previstas, que provocan sentimientos de desapego que hacen re-direccionar afectos y emociones por ambas partes.

En este contexto de incertidumbres, retornar se vuelve conflictivo, según Díaz, cuando la emigración, hace parte de un proyecto de vida o de mejora de situaciones anteriores, las condiciones del retorno serán asumidas como parte de la dinámica integral del movimiento migratorio. Si la migración, fuese forzada por situaciones de violencia y sin proyecto de vida los resultados pueden ser distintos (2009:14). Asimismo, si la migración debilita vínculos familiares, deja a la deriva proyectos y acuerdos iniciales y rompe abruptamente la cotidianidad familiar, el impacto psicosocial que producirá el retorno se expresará en la indiferencia de quienes se quedaron.

Es así que, el/la migrante como la familia ante la idea del retorno se preguntan: ¿Cuándo regresar?, ¿Cuándo regresará?, ¿Cómo regresará? ¿Por qué no regresa?, interrogantes que siempre están presentes, y que los vincula con sus familiares, amigos, su tierra y así mismo con un tiempo que los une a las imágenes dejadas al momento de la partida, las cuales se espera se conserven intactas al momento del regreso. Sin, embargo, es posible volver al espacio de la partida pero nunca se puede volver al tiempo de la partida, con sus emociones, rostros, nostalgias, deseos, lugares, aromas y colores.

No obstante, el retorno, como parte del proyecto migratorio, debe constituirse para cualquier migrante, bien sea por motivos económicos, personales o migración forzada, en un derecho que debería poder realizarse en condiciones dignas (Schramm, 2011:258). Esto implica a mi modo de entender, tres aspectos: en primer lugar, que los y/o las migrantes tenga la posibilidad de elegir cuando regresar, lo que daría cuenta que el retorno es una opción no una obligación o un deseo inalcanzable; en segundo lugar que las sociedades de origen como de destino provean de un contexto de oportunidades, a los y/o las migrantes, para que puedan movilizar el retorno, ello demanda que se flexibilicen las políticas restrictivas y de controles migratorios que obstaculizan la libre movilidad de los y las migrantes; y por último retomando a Schramm: los Estados deben 
entender a los migrantes más allá de su necesidad de fuerza de trabajo, es decir, como personas que tienen sus propios proyectos de vida que buscan alcanzarlos, usando estrategias específicas como la migración (2011:258).

Estas reflexiones iniciales, permiten tener un esbozo de la migración de retorno, más mi intención es dar cuenta a partir de una experiencia de la realidad social, en este caso desde los relatos de hijos e hijas, de sus significados construidos sobre el retorno de padre y/o madre. Desde esta perspectiva, se pretende cuestionar la adultocracia existente, que se legitima en las familias, al privilegiar la voz de los adultos y su superioridad, al considerar a hijos e hijas sujetos sin criterio para tomar decisiones, frente a si migrar, hacia donde, si se regresa o permanece en destino. De tal modo, que se anula o minimiza su participación y con ello su vivencia como hijos e hijas de migrantes. Para acercarme a la comprensión de estas experiencias en hijos e hijas he retomando sus relatos ${ }^{2}$, deteniéndome de manera especial en los acuerdos y los proyectos familiares.

\section{Sobre la metodología}

T a metodología de este estudio, se abordó desde la perspectiva de Strauss y Corbin (2002:3), como la "manera de pensar la realidad y de estudiarla". ــ Así la comprensión del retorno, de padres y/o madres migrantes desde los significados de hijos e hijas, constituyó una experiencia, a través de la cual me acerqué a sus construcciones subjetivas y con ello a sus vivencias cotidianas. Este abordaje, se fundamentó en la postura epistemológica de que todo acto es co-construido a partir de la interacción social comunicativa con otros y otras (Cubides y Durán, 2002:13).

En este sentido, dado que parto de concebir al ser humano como sujeto de conocimiento y co-constructor de su propia historia, el presente estudio se abordó desde el enfoque cualitativo, que comprendió, las realidades sociales desde la perspectiva del actor, interesa lo subjetivo, un abordaje situado y contextualizado en los sistemas de significados ligados a los mundos de interacción y prácticas compartidos socialmente (Castillo, 2003; Oquendo y Perneth, 2008).

El estudio, también se fundamentó en la perspectiva de género, como categoría de análisis facilita entender la simbología cultural, las relaciones de poder y los mecanismos que definen la forma como se valora a cada sexo, se le otorga una jerarquía y ciertos significados (Puyana et. al, 2003:268). Es así como desde esta perspectiva fue posible hacer relecturas según las significaciones de 
hijos e hijas frente al retorno visibilizando valoraciones, relaciones de poder $\mathrm{y} / \mathrm{o}$ redefiniciones.

En cuanto al método, en este estudio se concibió, según Strauss y Corbin, el conjunto de procedimientos y técnicas para recolectar y analizar datos (2002:3). Se utilizó, la entrevista semi-estructurada, como técnica que permitió propiciar encuentros interactivos-comunicacionales, por medio de los cuales se provocaron los relatos, como conversaciones en las que las personas expresan sus realidades, pero que de ninguna forma recogen mecánicamente la realidad, ya que solo son versiones construidas por cada persona y justifican su acción (Puyana, Motoa y Viviel, 2009:21).

En la selección de población por entrevistar, los criterios fueron los siguientes: que los hijos e hijas se encontraran entre los 9 y 24 años de edad, que el padre y/o madre migrante tuviera mínimo un año ${ }^{3}$ de haber migrado y que al momento de la entrevista los hijos e hijas en Colombia residieran en la ciudad de Cartagena. Además, estos criterios se establecieron teniendo en cuenta aspectos como la diversidad de género, edad, estrato social y la dependencia de los hijos e hijas hacia el/la migrante.

Se realizaron 13 entrevistas ${ }^{4}$, a hijos e hijas cuyos hogares estaban ubicados en los estratos sociales ${ }^{5}$ 1, 2 y 3 , de acuerdo a la clasificación del DANE ${ }^{6}$. Los dos primeros, agrupan a la población de estratos bajos y el último a la población de estrato medio. En la selección de los hogares, se encontraron varios tipos: hogares monoparentales femeninos o masculinos, hogares extensos, hogares superpuestos y hogares unipersonales, los cuales se configuraron antes, durante y después del proceso migratorio de padres y/o madres.

Para su selección se aplicó la técnica de la bola de nieve, que permitió a la entrevistadora a partir del contacto con los y las relatantes identificar a la siguiente persona a entrevistar y así sucesivamente. Es importante anotar aquí, que los hijos e hijas que accedieron a la entrevista lo hicieron de forma voluntaria, conté con su disposición para compartir a través de sus relatos su vivencia de la experiencia migratoria.

En relación a los países de destino, su selección se hizo de manera emergente, agrupándose así un conjunto de destinos diversos y comunes, entre ellos se destacaron: Venezuela, Italia y Aruba, que dan cuenta de la tradición migratoria en Colombia y, en la ciudad de Cartagena en particular. 


\section{Hijos e hijas de padres y/o madres migrantes:}

\section{hablan de retorno entre aquí y allá}

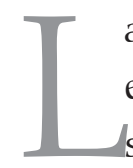

as familias anhelan continuamente el regreso de sus seres queridos, siempre están imaginando como sería volver a vivir juntos con quienes han partido si deciden volver al país de origen. Sin embargo, estos deseos que tienen mayor intensidad durante los primeros meses y años de partida, van menguando y en algunas ocasiones desapareciendo cuando se va aplazando continuamente la idea del retorno por parte de padres y/o madres migrantes, provocando en los hijos e hijas sentimientos de desesperanza e incredulidad ante el regreso.

Estos sentimientos, que se van alimentando en los hijos e hijas hacen que se vayan habituando a la ausencia del padre y/o madre migrante, y al mismo tiempo incorporen nuevos estilos de vida, que se expresan en cambios, en lo que se dejó, y que podrían entrar en conflicto con aquella imagen idealizada, que el/la migrante espera encontrar a su regreso. Tener que enfrentarse a estas posibles confrontaciones, conduce a que algunos hijos e hijas suelan vivir en medio de sentimientos contrapuestos, es decir, por una parte, se añora el deseo de un pronto regreso de padres y/o madres para volver a vivir juntos o, por el contrario, se desea que permanezcan en el país de destino mientras ellos/ as siguen construyendo sus trayectorias vitales junto a sus seres queridos en el país de origen.

Para acercarme a la comprensión de la experiencia migratoria en hijos e hijas he retomando sus relatos, visibilizando dos elementos constitutivos e interrelacionados que configuran sus significados construidos en torno al retorno de su padre y/o madre. Elementos que expresan cómo la migración adquiere diversas representaciones para hijos e hijas.

\section{Retorno como acuerdo presente, pero no definido}

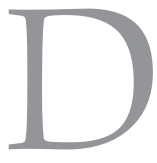

urante los procesos migratorios se definen determinados acuerdos o arreglos familiares entre el/la migrante y quienes se quedan, que se construyen a partir de vínculos desde lo local y transnacional. Los acuerdos o arreglos familiares permiten a las familias gestionar la vida cotidiana, los cambios de roles y las estrategias de reproducción social que en origen son necesarios para preservar la dinámica del grupo y mantener su vinculación con quien permanece en destino (Pedone, 2008:45).

En algunos relatos de hijos e hijas de padres y madres migrantes, se visibiliza que los acuerdos sobre el retorno se presentan como un momento conflictivo donde los límites entre el regreso y el asentamiento en el lugar de destino son 
difusos. Quizás por esta razón, al momento de la partida no existe claridad frente al cuando regresar y en consecuencia el tiempo de permanencia en el lugar de destino, lo cual resulta más incierto, porque si bien los padres y madres perciben en la migración una oportunidad para ellos y sus familias, nadie parte con la certeza de cómo será la vida en destino, lo que provoca continuos sentimientos de inseguridad, indecisiones y dudas. Algunos migran, como la madre de Sandra a probar suerte, se va a experimentar en otro lugar, y será la evolución de esta experiencia en destino la que irá definiendo su permanencia o regreso. Así lo recuerda ella:

"No, ella nunca dijo cuanto iba a durar, porque ella iba era a probar suerte, a ver como le iba, porque ella fue muy joven sin ninguna profesión, pero lo que sí tengo claro es que nunca nos iba a llevar para allá, porque precisamente iba a trabajar, porque ella no tenía una persona de confianza que nos cuidara" (Sandra H23. Madre migrante en Venezuela).

La madre de Sandra, lo que sí tenía claro al momento de la partida era que ella no se reunificaría con sus hijas en destino, su condición de migrante trabajadora no le permitiría asumir las funciones de cuidado, a ello se suma que además no contaba con una red de familiares que en destino apoyara estas funciones. Con respecto a esta situación, plantea Parella, las mujeres inmigrantes deben renunciar a educar presencialmente a sus propios hijos y tienen que ocuparse de los hijos de otras para poder hacer frente a sus necesidades económicas (citando a Momsen, 1999; Hondagneu-Sotelo 2000, 2003:131). Desde esta perspectiva, se puede hacer referencia a una fuga de cuidados, donde las mujeres de los países de origen se ven obligadas a delegar el cuidado de sus hijos e hijas a otros parientes o cuidadoras, para migrar a los países de destino, y dedicarse a cuidar allí a niños, ancianos y enfermos, en calidad de mucamas, niñeras o asistentes de guarderías y geriátricos (Russell, 2008:271).

A la anterior situación, se suma el hecho que las mujeres migrantes perciben menores ingresos y están concentradas en el sector doméstico, deben triplicar sus jornadas de trabajo y se enfrentan a mayores dificultades para acumular ingresos y acceder a una vivienda, requisito necesario para movilizar y proponer un eventual retorno. Estas situaciones presentes en el contexto de destino llevaron a algunas madres y padres migrantes a replantear los acuerdos iniciales de un posible retorno, que al momento de la partida previeron en un 
periodo de dos o tres años, a esta experiencia se refiere Katia, hija de madre migrante en Italia y Belkis, hija de madre y padre migrantes en Venezuela.

"Bueno, eso nunca quedó claro porque la idea era durar unos tres años y volver, y todo quedó igual, pero no fue así, porque se presentaron unos inconvenientes que nos desviaron de los objetivos que eran los tres años y entonces se tuvo que quedar un poco más" (Katia H23. Madre migrante en Italia).

"Desde un principio si se habló de retorno pero no seguro, ellos pusieron un plazo de 3 o 4 años para regresarse, no se cumplió, pero de quedarse a vivir allá nunca lo han tenido como opción, de trabajar y conseguir bastante dinero sí, para cuando ellos se regresen y depende de cómo avance el país allá"(Belkis H20. Madre y padre migrante en Venezuela).

Ahora bien, en este contexto de los acuerdos sobre el retorno hay que destacar que en algunos casos padres y/o madres migrantes no precisaron ningún tipo de acuerdo en relación a este proceso. Por lo tanto, se evidencia en los relatos que se produce la partida de padres y/o madres sin un mínimo de concertación o participación de hijos e hijas frente al regreso, y solo posterior a la partida se propone la interconexión local-transnacional entre ambos a partir de la movilización constante de los progenitores por medio de visitas esporádicas al país de origen. Las visitas como ritual se constituye en actos que contribuyen a fomentar, consolidar y amenizar las relaciones que expresan afectos, consideración y agradecimientos, de tal modo que para los hijos e hijas son un requisito a través del que se garantizaría la sostenibilidad del vínculo materno y paterno filial (Álvarez y Villamizar, 2004:239-267). A esta experiencia se refieren Carlos y Daniela.

"Que él se iba y venía en diciembre para pasarse la navidad acá, pero luego después se retractó que venía el próximo año para marzo, para mi cumpleaños y tampoco vino... Le dije: papi si va a venir cada diciembre que sea en serio ya, para no estar con falsas decisiones, si vas a venir, es porque vas a venir. Da la casualidad que no vino. ¿Y ese incumplimiento que te ha generado? Mucho, mucho rencor contra él. Porque al ver que no vino y dijo que iba a venir o sea, lo prometió ya cae en una mentira y nos está mintiendo y eso es malo mentirle contra nuestra propia familia que va a venir y no viene o sea, ya sería un rencor contra él por embustero, se ha puesto mentiroso." (Carlos H15. Padre migrante en Venezuela). 
"Ella me dijo que me iba a enviar toda la ropa, plata, que venía, y se duró dos años sin venir, y yo le dije: que si no venía que no me llamara más, que hiciera como si no tuviera hija, pero mi abuela, la mamá de ella me dijo que ella iba a venir, ella me dijo que venía para diciembre 15" (Daniela H15. Madre migrante en Venezuela). Exaltada

Las visitas entonces, se pueden configurar en acuerdos que refuerzan el vínculo con el padre y/o madre migrante, o por el contrario su incumplimiento puede provocar el descontento de los jóvenes con el/la migrante. La experiencia de Daniela y Carlos, nos ilustra sobre esta última situación, reflejando que lo pactado como acuerdos no necesariamente se materializa de forma genuina, hay contradicción entre lo acordado y aquello por lo que realmente se opta. Este accionar genera sentimientos de frustración, desengaño, desilusión y resentimiento en hijos e hijas, porque al darse el incumplimiento del acuerdo se va resquebrajando la confianza que reforzaba el vínculo entre ellos y el padre $y / o$ madre migrante.

Cuando se cumplen los acuerdos y las promesas, es posible que los hijos e hijas sientan que se materializa el proyecto familiar, pues estos nutren las expresiones de satisfacción y generan sentimientos de compañía y de seguridad por la corresponsabilidad en la familia (López, 2011: 135). En el caso contrario, sienten que no hay límites claros o coherencia entre lo establecido y su accionar, esto se percibe a través de los constantes aplazamientos "injustificados", el distanciamiento e indiferencia que refleja el cambio de actitud del migrante hacia los hijos e hijas, y que a su vez provoca el debilitamiento de los vínculos emocionales y de la continuidad de los referentes simbólicos, porque lo prometido no se cumple o se intenta forzar el cumplimiento de lo pactado como una obligación paterna o materna.

Las experiencias vivenciadas por los hijos e hijas, expresan la complejidad y heterogeneidad de los acuerdos frente al retorno. Algunos padres y/o madres parten cargados de incertidumbre porque desconocen como será la vida en destino, y condicionan a esta su regreso; otros si bien determinan un tiempo para el retorno supeditan su estadía en el país de destino al cumplimiento de las expectativas y metas, lo que provoca la redefinición de lo pactado; por último, se encuentran aquellos padres y/o madres que migraron sin establecer un mínimo acuerdo frente al retorno, lo que genera mayores angustias, tensiones y conflictos en las relaciones con los hijos e hijas. 


\section{Retorno como proyecto familiar: negociaciones y reconfiguraciones}

T a configuración de proyectos familiares, que vinculan al migrante con sus seres queridos en el país de origen, en especial con hijos e hijas, se constituye en el compromiso de enlace más fuerte que refuerza la conexión emocional en la distancia, en la medida que se comparten sueños, metas, expectativas e intereses mutuos, los cuales expresan que antes y después de la migración se mantienen los acuerdos, las promesas y las lealtades. En este sentido, un proyecto familiar se consolida a partir de elementos básicos como: la conexión emocional y afectiva, la organización económica para el sostenimiento, la formación del patrimonio familiar, la coparticipación en origen y destino en el cuidado de los integrantes, y las expectativas de futuro compartido entre la familia (López, 2011:129-132).

El interés compartido por el grupo familiar, en torno a su bien-estar desde el proyecto familiar comienza a circular entre aquí y allá, conectándose más allá de las fronteras. Ello conduce a una reorganización del hogar, que implica redefinición de la co-presencia física y la co-residencia que antes del evento migratorio conectaban la construcción de los proyectos familiares. A partir de la ausencia física se establecen nuevos medios de comunicación e interacción a través de los cuales los migrantes evocan su presencia en origen y ponen en circulación proyectos en los que están presentes sus intencionalidades, deseos y anhelos y los del grupo familiar.

Estos nuevos vínculos, reconfiguran la construcción de hogares glocales concebidos como escenarios de encuentro familiar, que articulan el hogar del país de origen y el del país de destino, mediante la interconexión y la sostenibilidad del sentido relacional y vinculante entre los integrantes, no obstante estar ubicados en países diferentes y distantes (Glick Schiller, Basch, Blanc-Szanton, 1992:24). Los siguientes relatos dan cuenta de esta vinculación:

"¿Qué es para ti un proyecto familiar? "Son como todas esas metas, o proyectos que la familia se hace para cumplir en algún momento, yo creo que en este caso si hay un proyecto familiar. Un día mi papá me dice: "hija ya faltan cuatro semestres", y yo no tengo más hermanos ni por parte de papá ni de mamá y entonces cumplir con mis estudios, lo económico, por ejemplo: ellos dijeron "vamos a terminar la otra parte de la casa", desde el año pasado y ya este año sí, son proyectos para mí y para ellos" (Karen H18. Madre y padre migrante en Venezuela). 
"Yo tengo una cosa desde chiquitica, como te dije, yo tenía mucho apego con mi abuela y entonces la gente piensa que toda la crianza fue de mi abuela, tengo mucha confianza con mi abuela, pero yo espero que llame mi mamá para contárselo a mi mamá, porque hay cosas que solo entiende ella, que le he dicho, y eso no cambia" (Isabel H19. Madre migrante en Venezuela).

De esta manera, en las familias con proyectos familiares la presencia del padre y/o madre migrante a través de la reconfiguración de escenarios y relaciones vinculantes se conecta con la vida de hijos e hijas, gracias al establecimiento de mecanismos de orden simbólico o material desde los cuales ellos continúan ejerciendo sus funciones maternas y paternas de crianza, socialización y provisión de bienestar emocional y económico. Esta conexión, expresa el decidido compromiso de los y las migrantes con el cumplimiento de los proyectos del grupo, lo que redunda en sentimientos de satisfacción en los hijos e hijas porque a pesar de las distancias socio-espaciales se mantiene y da continuidad en el tiempo a lo pactado.

Cuando hijos e hijas vivencian estos sentimientos y las familias se conectan decididamente a través de ellos, los proyectos familiares logran tener mayor asidero dentro del grupo familiar. Esto puede ocasionar que el padre y/o madre migrante una vez alcanzado los objetivos comunes propuestos en la distancia, donde prevalece el bienestar de hijos e hijas se avecinen a la concreción del retorno como proyecto familiar, que expresa el éxito y logro de gran parte de los objetivos del proyecto migratorio, y cuyo cumplimiento motivan la búsqueda de la unidad del grupo familiar. Retomando los planteamientos de López, para los hijos e hijas la expectativa de reunificación o retorno, expresa claramente el deseo de estar junto al padre y/o la madre, de compartir la cotidianidad familiar y la interacción cara a cara; este deseo es para ellos y ellas el sentido de unidad familiar (2011:140).

En algunos casos es importante tener en cuenta que las familias en conjunto redefinen y negocian por diversos motivos los proyectos iniciales, pero no se abandona el deseo de la unidad familiar. A estas experiencias se refieren Karen e Isabel:

"Mi papá dice que cuando yo termine la universidad él ya se viene, porque él dice que ya no tiene que estar trabajando más, y que ya va a tener una vida más tranquila y relajada"(Karen H18. Madre y padre migrante en Venezuela). 
"El proyecto familiar si cambió cuando nació mi hermanito, él tiene 5 años, él fue con otro señor allá, entonces mi mamá planea otras cosas, ella dice: "yo tengo que volver porque Nicolás no puede estudiar aquí en Venezuela", y ella sabe que en ese aspecto su familia no la va a dejar sola, y pues sí, se plantea la idea que se comprara una casa en Barranquilla, de estemos juntas otra vez" (Isabel H19. Madre migrante en Venezuela).

Mientras para algunos hijos e hijas es posible construir proyectos familiares en la distancia con el padre y/o madre migrante, para otros situaciones como: el nulo establecimiento de acuerdos al momento de la partida, la migración del padre o madre durante la etapa de la infancia, y su distanciamiento abrupto o progresivo de las obligaciones y responsabilidades se convirtieron en situaciones que derivaron en el distanciamiento emocional entre ambos. De manera particular, para las madres migrantes separarse de sus hijos, es una elección que implica una terrible tristeza, dado su rol tradicional en el cuidado. A esos hijos se les ha quitado la presencia diaria de la madre, y con ella la expresión cotidiana de su amor, generando pérdida del afecto (Russell, 2008:271).

Esto provocó, que hijos e hijas buscaran en sus cuidadores/as suplir aquellos vacios emocionales que las distancias y ausencias fueron acentuando. Las relaciones cercanas con cuidadores/as basadas en la confianza, el afecto, la protección y el cuidado se convierten entonces en los vínculos fuertes mediante los cuales hijos e hijas construyen los proyectos familiares, así lo relata Sandra:

"Bueno la verdad no, yo fui construyendo mi proyecto familiar con mi tía, y ella (mamá) siempre nos hacia ese énfasis que ella iba a venir de nuevo, que mi tía nos estaba cuidando, pero que ella venía. Siempre me preguntaba “¿Cómo quieres la habitación de tu hermanita? ¿Cómo está quedando la casa? ¿Cómo quieres tu habitación?", y cuando ella me preguntaba eso yo no respondía nada o iah ya?, -sí está bonita- y ya, pero era porque yo no me pintaba viviendo en esa casa, pero ella si inventaba planes y más con mi hermanita, porque ella estaba más pequeña pero conmigo no, porque ya yo estaba más grande, y ella dormía con mi hermanita en la casa que estaba construyendo y yo dormía dos días con ella y los otros cinco días con mi tía, mi excusa era que todas mis cosas estaban allá"(Sandra H23. Madre retornada de Venezuela).

No es extraño, que algunos hijos e hijas sientan que los proyectos que sus padres y/o madres migrante, estiman como familiares, sean percibidos por 
ellos como ajenos y extraños, y por tanto no revistan mayor interés. Esto puede ser comprensible, porque en la medida que hijos e hijas construyen sus proyectos familiares en origen junto a sus cuidadores/as se sienten complacidos y satisfechos, mientras que los proyectos del padre y/o madre migrante son relegados, y no se asumen como parte de objetivos y deseos comunes y compartidos. Por lo tanto, ante un eventual retorno o reunificación es posible que los hijos e hijas tomen distancia y se muestren poco receptivos a vincularse al nuevo proyecto de sus progenitores. Esta situación puede desembocar en conflicto porque se contrapone el debe ser del padre y/o madre migrante a los deseos de los hijos e hijas, debido a que se le impone u obliga sin ninguna negociación que acepten el nuevo proyecto, desconociendo que ante su ausencia han reorganizado su proyecto familiar.

Ahora bien, entendemos que todo proyecto familiar implica el establecimiento de acuerdos sostenibles en el tiempo que deben ser negociados y concertados, y en ocasiones redefinidos por todos los integrantes del grupo familiar, de tal modo que se vinculen en el logro de intereses comunes. Algunos hijos e hijas dan cuenta en sus relatos que si bien es cierto el/la migrante en la distancia comienza a configurar un proyecto de retorno que lo vincula con el grupo familiar de origen, el deseo de estar juntos aquí o allá no constituye para ellos un proyecto familiar por diversos motivos: ausencia de acuerdos, partida del migrante en la etapa de la infancia, privaciones emocionales y la ganancia de autonomía e independencia para decidir sobre sus propios proyectos, según sus motivaciones, expectativas y anhelos. Esto los lleva a considerar que si hay un proyecto, se trata de un proyecto de pareja, donde el padre y/o madre migrante desea unirse al cónyuge que permanece en el país de origen. Ellos/ as no se siente vinculados con un proyecto familiar de retorno, pues no están dispuesto a renunciar a sus proyecto personales. Esta experiencia es referida así por Marcela:

"La verdad no, porque eso también iría en los acuerdos y eso pues nunca se ha hablado, con mi mamá sí, ella antes de hacer unas cosas nos pregunta que queremos, pero con mi papá no...Bueno ella siempre ha querido que él regrese y estar juntos, sea allá o acá, pero la circunstancia no se han dado, unidos sí, comunicándose, pero así. Es difícil, el proyecto que ellos quieren es estar juntos pero mis proyectos personales son totalmente diferente a lo de ellos, yo sí quiero viajar, irme a otro lado a estudiar y vivir sola, ese es más bien un proyecto de pareja no familiar, porque ya uno crece, y todo eso, yo creo que a mi mamá de pronto si le hubiese gustado pero ajá" (Marcela H22. Padre migrante en Aruba). 
En otros grupos familiares los hijos e hijas se enfrentan a la incertidumbre en torno a la consolidación de un proyecto familiar de retorno, porque el/la migrante debido a sus constantes vacilaciones e indecisiones tiene dificultades para concretar en conjunto con los hijos e hijas el tiempo, el lugar y los proyectos para estar juntos aquí o allá. Esta situación suele presentarse cuando el/la migrante al escapar de una relación de pareja conflictiva, no resuelve los términos de su relación y a su regreso sigue manteniendo el vínculo, generando malestar en los hijos e hijas; otra situación puede estar referida a la seguridad y acomodación que ha ido estableciendo el/la migrante en el país de destino, que le genera la sensación de permanecer, pero este sentimiento entra en tensión cuando los vínculos afectivos se encuentran en origen, y no se ha negociado con ellos/as una posible reunificación. El relato de Yina, da cuenta de esta experiencia:

"Pues no sé si tenemos o si podemos construir un proyecto familiar porque mi mamá es tan indecisa con las cosas, nosotros queremos que ella ni siquiera viviera más con mi papá, y que cuando viniera ni volteara a ver a mi papá y que las cosas fueran más que todo fuera con nosotros y ya... de las dos posibilidades hemos hablado muchísimas veces pero nunca termina cediendo de un todo si es para aquí o para allá, es que no sé si ella estaría dispuesta a quedarse, porque cuando ya lleva dos meses aquí dice: "que se está volviendo loca, definitivamente esta vida aquí no es como la de allá". La verdad es que no sé si nosotros estaríamos dispuestos a irnos o ella a quedarse aquí" (Yina H18. Madre migrante en Venezuela).

La experiencia de Yina, pone de presente también que en la consolidación de un proyecto familiar cuya intencionalidad es favorecer el bien-estar de los hijos e hijas, padres y/o madres desde una actitud reflexiva deben renegociar a que están dispuesto a ceder ellos/as para lograr la realización del proyecto, pues muchas veces se aferran a sus necesidades y proyectos personales, y los priorizan y definen como satisfactores del grupo familiar en general. Estas situaciones generan conflictos y tensiones en los hijos e hijas, ya que los padres y/o madres los mantienen en la incertidumbre y la disyuntiva entre el permanecer en destino o quedarse en origen, pues no se establece un acuerdo definitivo; por otra parte, también los cuestiona el hecho de confrontar sentimientos opuestos, como se expresa: La verdad es que no se si nosotros estaríamos dispuestos a irnos o ella a quedarse aquí. 
El proyecto familiar, demanda así de unas disposiciones personales que transiten de lo individual a lo familiar, donde las necesidades y demandas de los hijos e hijas son reconocidas, y se tome distancia de un proyecto adultocéntrico. Pues un mayor énfasis en los proyectos individuales del padre y/o madre migrante contribuye a debilitar el proyecto familiar, provocando la exclusión de los hijos e hijas de los nuevos proyectos de vida, se cumple con la proveeduría económica, pero entre sus planes no está ni la reunificación, ni el retorno, ni un proyecto compartido.

\section{Algunas notas para concluir, dejando abierta la discusión}

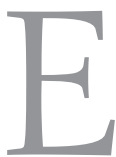
ntender la migración internacional como proceso, impulsa a comprender que la migración no se desarrolla de forma lineal en las experiencias de quienes migran y el grupo familiar que permanece en origen, sino que en ella se producen una variedad de movimiento y contra-movimientos donde las trayectorias migratorias pueden incorporar procesos de retorno familiar que expresan las conexiones entre el país de origen o destino. De esta manera, en algunos grupos familiares los y las migrantes y sus familias van configurando expectativas, anhelos y proyectos futuros en torno a la migración donde los deseos de volver a estar juntos, aquí o allá se constituyen en ideales de cada uno de los integrantes de las familias.

En este sentido, la migración pasa a ser un proceso complejo, puesto que implica una heterogeneidad de movimientos y contra-movimientos, donde los migrantes pueden movilizarse sucesivamente entre aquí y allá, en la medida que van construyendo, deconstruyendo y reconstruyendo sus trayectorias migratorias, dando cuenta que el proceso migratorio no culmina con el mero acto de llegada al país destino, sino que en el interviene y circulan variedad de momentos y sujetos. Es así, como el retorno se constituyen en un proceso vital que imprime una dinámica constante que reconfigura al evento migratorio.

El acercamiento a los significados, que los hijos e hijas construyen en torno al retorno de sus padres y/o madres permiten reconocer los elementos subjetivos que expresan como en algunos casos existe una planificación, preparación y arreglos en torno a la migración, de tal modo que hijos e hijas viven el proceso migratorio de padres y/o madre con menos incertidumbres y se incorpora como parte del proyecto familiar. Mientras en otros, estos procesos son abruptos, inesperados y con una nula participación de los hijos e hijas, que hacen que se experimenten tensiones y malestares frente al proceso migratorio. 
Por otra parte, es importante señalar como dentro del proceso migratorio los proyectos familiares imprimen una interconexión entre origen y destino. Esta interconexión, que vincula a padres y/o madres con sus seres queridos en el país de origen, en especial con hijos e hijas, constituyendo el compromiso de enlace más fuerte que refuerza la conexión emocional en la distancia, en la medida que se comparten sueños, metas, expectativas e intereses mutuos. Por ello, algunos hijos e hijas a lo largo del proceso migratorio siempre imaginan como será el posible regreso, aun cuando piensan en las tensiones y los conflictos que supondría volver a vivir con quien ha permanecido en la distancia, no obstante el deseo de volver a estar cerca de su padre y/o madre permanece.

En otros casos, hijos e hijas han construido sus proyectos personales alejados física y emocionalmente de sus progenitores, por lo tanto los significados construidos en torno al retorno no corresponden a un proyecto familiar, por ello la idea de un posible retorno del padre y/o madre genera tensiones, resistencias y conflictos.

\section{BIBLIOGRAFÍA}

ÁLVAREZ, Alexandra y VILLAMIZAR, Thania (2004). La visita: Creencias y concepciones sobre la territorialidad. Boletín antropológico. Mayo-agosto Vol. 22 No. 061. Universidad de los Andes. Mérida, Venezuela.

ARANGO, Luz Gabriela; LEÓN, Magdalena y VIVEROS, Mara. (Comp.) (1995). Género e identidad. Ensayos sobre lo femenino y lo masculino. Tercer Mundo. S.A. Bogotá.

CASTILLO, Elizabeth. (2003), Lo científico de la investigación cualitativa: Viejos dilemas, nuevas posturas. En: Revista Nómadas. Desafíos de la investigación cualitativa. Número 18. Departamento de Investigaciones. Universidad Central.

CUBIDES, Humberto y DURÁN, Armando. (2002). Epistemología, ética y política de la relación entre investigación y transformación social. En: Revista Nómadas № 17 Investigación y Transformaciones Sociales. Universidad Central. Bogotá, Colombia.

DANE. Página Web: http://Www.dane.gov.co/. Búsqueda realizada el 23 de julio de 2013.

DÍAZ, Luz Marina. (2009). La quimera del retorno. En: Diálogos migrantes. Migración y retorno. Revista del Observatorio Colombo-Ecuatoriano de Migraciones OCEMI. N 4. ISSN: 2027-1867. Fundación Esperanza.

DURAND, Jorge. (2004). Ensayo teórico sobre la migración de retorno. El principio del rendimiento decreciente. Cuadernos Geográficos, 35 (2004-2), 103-116. redalyc.uaemex.mx/ pdf/171/17103507.pdf. Búsqueda realizada el 03 de enero de 2011.

No. 15. Agosto de 2015 PalObra 
ENMIR. Encuestas nacional sobre migraciones internacionales y remesas 2008-2009. Resultados generales de migraciones internacionales y remesas. Observatorio Distrital de Migraciones- Alcaldía Mayor de Bogotá, Observatorio Colombiano de Migraciones-Fundación Esperanza-Red Alma Máter.

GLICK SCHILLER, N. BASCH, L. Y C. BLANC-SZANTON (Eds) (1992). Towards a transnational perspective on migration, Vol.645. New York: The New York Academy of Sciences.

GONZÁLEZ, Pulido Alejandro. (2006). Aproximación a la migración de retorno en Colombia. En: RUIZ, Nubia, GONZÁLEZ Alejandro, AYSA, María y ROLDÁN Jhon. Desplazamiento, movilidad y retorno en Colombia. Dinámicas migratorias recientes. Cuadernos del Centro de Investigaciones sobre Dinámica Social. Serie III. Universidad Externado de Colombia.

RUSSELL, Hochschild Arlie. (2008). La mercantilización de la vida íntima. Apuntes de la casa y el trabajo. Traducido por Lilia Mosconi. Katz Editores. Buenos Aires.

LÓPEZ, Montaño Luz María. (2011). Proyecto familiar y familia en situación de transnacionalidad en Colombia. Revista Latinoamericana Estudios de Familia. Vol. 3, enero - diciembre. Universidad de Caldas. Facultad de Ciencias Jurídicas y Sociales. Departamento Estudios de Familia.

OQUENDO, Lorduy Anatali y PERNETH, Pareja Leidy. (2008). Reflexionando la investigación cualitativa a partir del estudio de la paternidad y la maternidad innovadora en Cartagena de Indias. Aportes a la relación entre investigación y trabajo social. Trabajo de grado para optar al título de Trabajadora Social. Facultad de Ciencias Sociales y Educación. Universidad de Cartagena.

OQUENDO, Lorduy Anatali. (2012). Informe final proyecto de investigación: "Significados que construyen hijos e hijas en torno al retorno o la reunificación familiar a partir de la migración internacional del padre y/o madre. Caso Cartagena de Indias". Universidad de Cartagena-Colciencias.

PARELLA, Rubio Sonia. (2003). Mujer, inmigrante y trabajadora: La triple discriminación. Anthropos Editorial.

PEDONE, Claudia. (2008). "Varones aventureros" vs. "madres que abandonan": Reconstrucción de las relaciones familiares a partir de la migración ecuatoriana1. REMHU. Revista Interdisciplinar de Movilidad Humana, Ano XVI, No 30.

PUYANA, Yolanda. (Comp.) (2003). Padres y madres en cinco ciudades colombianas. Cambios y permanencias. Almudena Editores. Bogotá-Colombia.

PUYANA, Yolanda; MOTOA, FLÓREZ Ayda y VIVIEL, CASTELLANOS Adriana. (2009). Entre aquí y allá las familias colombianas transnacionales. Fundación Esperanza. Bogotá- Colombia.

PUYANA, Yolanda; MICOLTA, Amparo; PALACIOS, María Cristina; CANO, Nohora; JIMÉNEZ, Blanca; RODRÍGUEZ, Mercedes; BONILLA, Gloria; ESCOBAR, María Cénide; MALDONADO, María Cristina; MORAD, María del Pilar; SÁnCHEZ, Gloria y LóPEZ, Luz María, et al. (2008). Cambios y conflictos de los grupos familiares frente a la migración internacional. 452/08 Financiación de proyectos de investigación - año 2008. Ciencias Sociales y Humanas. Presentado en Convocatoria Colciencias. 
SCHRAMM, Christian. (2011). Retorno y reinserción de migrantes ecuatorianos. La importancia de las redes sociales transnacionales. Revista CIDOB d'Afers Internacionals, núm. 93-94. Página Web: www.cidob.org/ca/content/.../241-260_CHRISTIAN+SCHRAMM.pd. Búsqueda realizada el 20 de mayo de 2011.

STRAUSS, Anselm y CORBIN, Juliet. (2002). Bases de la investigación cualitativa. Técnicas y procedimientos para desarrollar la teoría fundamentada. Colombia. Facultad de Enfermería de la Universidad de Antioquia. Editorial. Universidad de Antioquia. 